\title{
Mixing Things Up
}

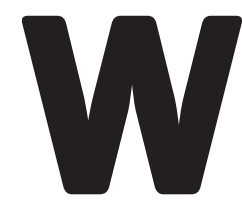

e've been experimenting with a new editorial model. Previously, issues of $X R D S$ have been directed by one or two Feature Editors, who have a particular interest in a subject area. For example, James Stanier headed up the "Changing Face of Programming" issue; Michael Bernstein and Inbal Talgam put together the "Comp-YOU-ter" issue on Human Computation. Being an Issue Editor means lots of conversations with the XRDS team to figure out themes, tracking down and inviting experts to contribute articles, and reviewing articles submitted through our online portal.

With this issue, we reached out beyond $X R D S$, and invited Jon Froehlich to be Issue Editor. By the time you read this, Jon will be weeks away from defending his Ph.D. thesis at the University of Washington. His research interests include persuasive technology, personal informatics, urban informatics, and environmental sustainability. Because of his high profile work in these areas, we knew he was the man to lead this issue on Green Technology!

You might have already detected this issue of $X R D S$ is a little heavier

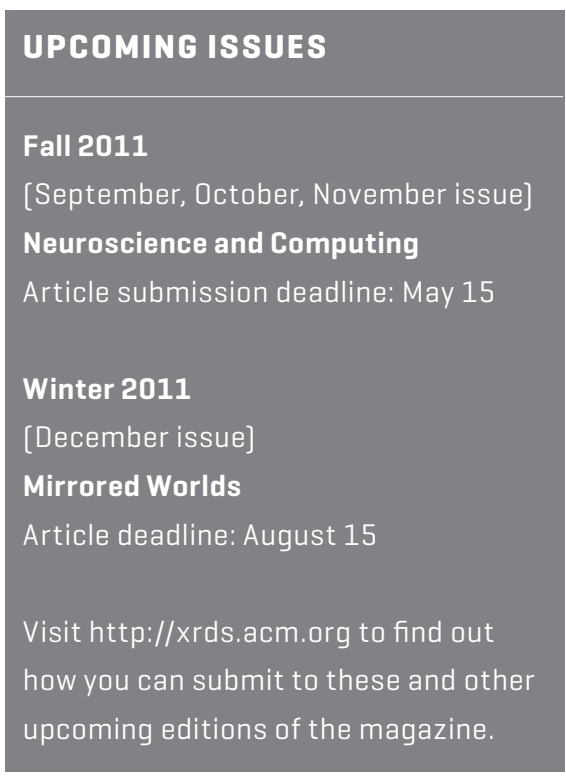

than past issues. That's because Jon went all out, and brought in an incredible array of authors and topics to explore eco-friendly technologies. For an overview of this issue, hit up his Init column on p.5. And if you find the subject matter particularly exciting, we've included a listing of top graduate programs with a focus in this area (see Pointers on p.63).

\section{The Team}

Our masthead is also seeing quite a few changes. After nearly two years at the helm of our Departments (basically, all the content outside of feature articles), Tom Bartindale is stepping down. Tom was instrumental in the $X R D S$ relaunch, helping to formulate much of the new look and content of the magazine. With his newfound free time, Tom will be wrapping up his Ph.D. studies at the University of Newcastle. James Stanier will be taking over as Departments Chief starting next issue (Fall 2011). If anyone can fill such big shoes, it's James.

I am also pleased to announce that Anirvana Mishra will be taking on the role of Web Editor. A new website was launched alongside XRDS (http:// xrds.acm.org/) and we're going to try to bring some unique content and features to this platform. If you have
66

You might have
already detected
this XRDS is a
little heavier than
past issues. That's
because Jon
[Froehlich] went all
out, and brought in
an incredible array of
authors and topics to
explore eco-friendly
technologies."

ideas, or would like to help, Anirvana would love to hear from you. Finally, with the departure of Jill Duffy from ACM last issue, $X R D S$ has been in the capable hands of Diane Crawford, who helped put together this issue. Starting next issue and moving forward, our Managing Editor at ACM headquarters will be Denise Doig. We're looking forward to working with her!

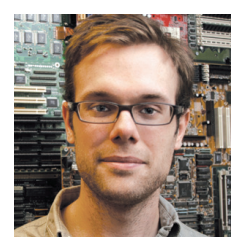

Chris Harrison is a Ph.D. student in the Human-Computer Interaction Institute at Carnegie Mellon University. Before coming to CMU, Harrison worked at IBM Research and AT\&T Labs. He has since worked at Microsoft Research and Disney Imagineering. Currently, Harrison is investigating how to "interact with small devices in big ways" through novel sensing technologies and interaction techniques. 